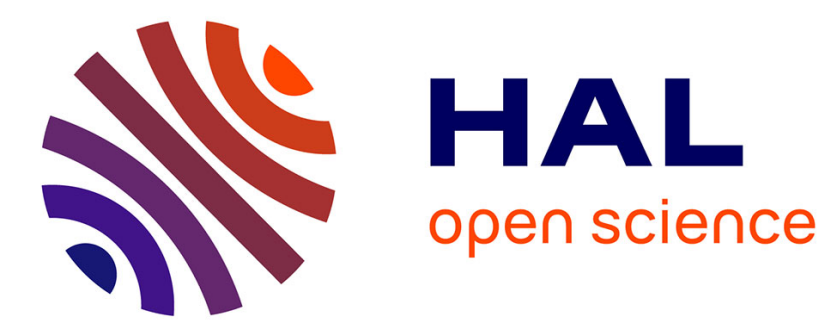

\title{
Recently discovered properties of aspirin may be doubly helpful in bipolar disorders.
}

\author{
Guillaume Fond, Nicolas Girerd, Françoise Clavel, Ryad Tamouza, Marion
}

Leboyer

\section{- To cite this version:}

Guillaume Fond, Nicolas Girerd, Françoise Clavel, Ryad Tamouza, Marion Leboyer. Recently discovered properties of aspirin may be doubly helpful in bipolar disorders.. Medical Hypotheses, 2014, 82 (5), pp.640-1. 10.1016/j.mehy.2014.02.028 . inserm-00966007

\section{HAL Id: inserm-00966007 https://www.hal.inserm.fr/inserm-00966007}

Submitted on 26 Mar 2014

HAL is a multi-disciplinary open access archive for the deposit and dissemination of scientific research documents, whether they are published or not. The documents may come from teaching and research institutions in France or abroad, or from public or private research centers.
L'archive ouverte pluridisciplinaire $\mathbf{H A L}$, est destinée au dépôt et à la diffusion de documents scientifiques de niveau recherche, publiés ou non, émanant des établissements d'enseignement et de recherche français ou étrangers, des laboratoires publics ou privés. 


\section{Accepted Manuscript}

Correspondence

Recently discovered properties of aspirin may be doubly helpful in bipolar disorders

Guillaume Fond, Nicolas Girerd, Françoise Clavel, Ryad Tamouza, Marion Leboyer

PII: S0306-9877(14)00099-1

DOI: http://dx.doi.org/10.1016/j.mehy.2014.02.028

Reference: $\quad$ YMEHY 7526

To appear in: $\quad$ Medical Hypotheses

Received Date: $\quad 18$ November 2013

Accepted Date: $\quad 24$ February 2014

Please cite this article as: G. Fond, N. Girerd, F. Clavel, R. Tamouza, M. Leboyer, Recently discovered properties of aspirin may be doubly helpful in bipolar disorders, Medical Hypotheses (2014), doi: http://dx.doi.org/10.1016/ j.mehy.2014.02.028

This is a PDF file of an unedited manuscript that has been accepted for publication. As a service to our customers we are providing this early version of the manuscript. The manuscript will undergo copyediting, typesetting, and review of the resulting proof before it is published in its final form. Please note that during the production process errors may be discovered which could affect the content, and all legal disclaimers that apply to the journal pertain. 
Letter

\section{Recently discovered properties of aspirin may be doubly helpful in bipolar disorders}

Running title : aspirin in bipolar disorders

Guillaume Fond* a ${ }^{\text {a }}$ MD; Nicolas Girerd ${ }^{\mathrm{b}}$, MD, MSc, Françoise Clavel $^{\mathrm{d}}$, Ryad Tamouza $^{\mathrm{c}^{* * *}}, \mathrm{MD} \mathrm{PhD}$, Marion Leboyer ${ }^{\mathrm{a}^{* *}}, \mathrm{MD} \mathrm{PhD}$.

${ }^{a}$ Université Paris Est-Créteil, Pôle de psychiatrie des hôpitaux universitaires H Mondor, DHU Pe-Psy, INSERM U955, Eq 15 Psychiatrie Génétique, Fondation FondaMental Fondation de coopération scientifique en santé mentale,.

${ }^{\mathrm{b}}$ INSERM, Centre d'Investigations Cliniques 9501, Université de Lorraine, CHU de Nancy, Institut Lorrain du cœur et des vaisseaux, Nancy, France

'Jean Dausset Laboratory \& INSERM, UMRS 940, Hôpital Saint Louis, Paris, France dUnité de Recherches en Epidémiologie des Cancers de I'INSERM (U287), Institut Gustave Roussy, Villejuif, France.

** Both authors equally directed this work.

*Corresponding author

Dr Guillaume Fond

Pole de Psychiatrie, Hôpital A. Chenevier, 40 rue de Mesly, Créteil F-94010

tel (33)1 78682372 fax (33)1 78682381

guillaume.fond@gmail.com

word count 501 
Dear editor,

While aspirin is an ancient folk remedy sold over-the-counter for more than a century and since used in a lot of disorders, new properties of aspirin are still discovered to this day.

Aspirin may be doubly helpful in bipolar disorder. First, bipolar disorder may be the result of a pre-inflammatory multisystemic disorder[1] that affects not only mood regulation but also cardiovascular status. Patients with bipolar disorder may hence be seen as a population at intermediate risk for cardiovascular disease, and aspirin may be helpful in primary prevention in this population. However trials are warranted to confirm the benefit of aspirin in this indication [5].

Second, new properties of aspirin have been recently discovered, especially antiinflammatory properties, which may be particularly interesting in bipolar disorder that is strongly associated with immunologic and inflammatory dysfunctions [6]. If bipolar disorders may result in some cases in a chronic inflammation of central nervous system (CNS) (due to microglia activation), fixing this inflammation may thus improve mood symptomatology and possibly prevent cognitive decline associated with this disorder. ASA is 50 to 100 -fold more potent in inhibiting platelet cyclooxygenase $1(\mathrm{COX}-1)$ than monocyte cyclooxygenase 2 (COX-2) activity [2]. Choi et al [3] proposed in a recent review to reconsider the prevailing hypothesis that, by being the isoform induced in response to inflammatory stimuli, COX-2 is the most appropriate pharmacological target for anti-inflammatory therapy, and suggested that COX-1, owing to its predominant localization in microglia, is the major player in mediating the inflammatory response. It has even been suggested that mood stabilizers and antidepressive agents may improve depressive symptomatology by the inherent anti-inflammatory properties of some of them.

Preliminary data obtained in bipolar disorders suggest beneficial effects on depressive symptoms that are improved using aspirin (acetyl salicylic acid (ASA)) in low doses (in which ASA would inhibit COX-1 but not COX-2)..

In a large pharmaco-epidemiological study, Stolk et al [4] tested in 5145 patients receiving lithium whether non-steroidal anti-inflammatory drugs (NSAIDs) or glucocorticoids would improve bipolar symptoms (based upon the assumption that lithium treatment is relatively specific to individuals with bipolar disorders). The 
main outcome measure was a calculated incidence density of medication events (change in the type or numbers of psychotropic medications prescribed or increase $(>30 \%)$ in the psychotropic drug dose). Subjects receiving low-dose ( $\leq 80 \mathrm{mg} /$ day) aspirin were $17 \%$ less likely to have a medication event, a finding that remained significant after adjusting for age, sex, chronic disease score and healthcare utilization. Aspirin and lithium may also exert synergistic effects in forming antiinflammatory brain metabolites [4]. These preliminary observations thus appeared consistent with the hypothesis that $\mathrm{COX}-1$ inhibitors can reduce neuro-inflammatory processes with consequent beneficial improvement of bipolar illness.

It was relatively recently discovered that aspirin administration triggers the biosynthesis of the so-called aspirin-triggered lipoxins (ATLs) (the term "lipoxin" is an acronym for lipoxygenase interaction products). Lipoxins and ATLs are generated from arachidonic acid and are considered to act as 'braking signals' in inflammation, dampening the second-phase inflammatory response via the modulation of microglia [7]. Microglia are considered the "resident macrophages" of the brain and play an essential role in innate immunity, homeostasis, and neurotropic support in the central nervous system. Microglia perform routine maintenance and immune surveillance in their resting state. Once activated, either by injury or an immune stimulus, microglia secrete a variety of pro-inflammatory molecules that may cause neurodegeneration if their up-regulation lasts for an extended period of time [8]. Aspirin also modulates innate and adaptive immune responses : aspirin can suppress the lymphocyte B antibody-mediated humoral immune response, as well as the neutrophil and monocyte/macrophage-mediated innate immune responses (by decreasing inter alia neutrophil cells' extravasation and their adherence to the endothelial lining, a distinctive step in the innate immunity) (for a complete review, see [9]). In addition to its strictly speaking anti-inflammatory and immune properties (that are also neuroprotective), aspirin was found to enhance adenosine production [10], to modulate nitric-oxide synthesis [11] and to inhibit nuclear factor-kappa B (NF-kB) transcriptional pathway [12], all these mechanisms potentially play a role in its neuroprotective properties.

Basselin et al demonstrated that aspirin extinguishes CNS inflammation at low and high therapeutic doses in rats [13]. In humans, the anti-inflammatory properties of low doses of aspirin have also been demonstrated in a population of subjects with 
metabolic syndrome (that is frequently comorbid with bipolar disorders) : 100-300 $\mathrm{mg} / \mathrm{d}$ aspirin decreased blood levels of Tumor Necrosis Factor alpha (TNF-alpha), Interleukine 6 (IL-6) and high sensitivity C-reactive protein (hs-CRP), three major inflammatory markers that have been found to be disturbed in patients with bipolar disorders [14] .

Aspirin may be doubly helpful in bipolar disorders, for prevention of cardiovascular events as well as an anti-inflammatory drug that may influence and protect the central nervous system.

Conflicts of interest : All authors declared no conflict of interest in the last 2 years.

No funding source.

Acknowledgments : This work was supported by INSERM, Assistance Publique Hôpitaux de Paris, RTRS Santé Mentale (Fondation Fondamental) and by Agence Nationale pour la Recherche (ANR: NEURO 2009, V.I.P. project). This work was supported (in part) by the Investissements d'Avenir program managed by the ANR under reference ANR-11-IDEX-0004-02.

[1] M. Leboyer, I. Soreca, J. Scott, M. Frye, C. Henry, R. Tamouza, et al., Can bipolar disorder be viewed as a multi-system inflammatory disease?, J Affect Disord 141 (2012), pp. 1-10.

[2] F. Cipollone, P. Patrignani, A. Greco, M.R. Panara, R. Padovano, F. Cuccurullo, et al., Differential suppression of thromboxane biosynthesis by indobufen and aspirin in patients with unstable angina, Circulation 96 (1997), pp. 1109-1116.

[3] S.H. Choi, S. Aid and F. Bosetti, The distinct roles of cyclooxygenase-1 and -2 in neuroinflammation: implications for translational research, Trends Pharmacol Sci 30 (2009), pp. 174-181.

[4] P. Stolk, P.C. Souverein, I. Wilting, H.G. Leufkens, D.F. Klein, S.I. Rapoport, et al., Is aspirin useful in patients on lithium? A pharmacoepidemiological study related to bipolar disorder, Prostaglandins Leukot Essent Fatty Acids 82 (2010), pp. 9-14.

[5] C. Crump, K. Sundquist, M.A. Winkleby and J. Sundquist, Comorbidities and mortality in bipolar disorder: a Swedish national cohort study, JAMA Psychiatry 70 (2013), pp. 931-939. 
[6] K. Munkholm, M. Vinberg and L. Vedel Kessing, Cytokines in bipolar disorder: a systematic review and meta-analysis, J Affect Disord 144 (2013), pp. 16-27.

[7] D.W. Gilroy, The role of aspirin-triggered lipoxins in the mechanism of action of aspirin, Prostaglandins Leukot Essent Fatty Acids 73 (2005), pp. 203-210.

[8] R. Medeiros, M. Kitazawa, G.F. Passos, D. Baglietto-Vargas, D. Cheng, D.H. Cribbs, et al., Aspirin-triggered lipoxin a4 stimulates alternative activation of microglia and reduces Alzheimer disease-like pathology in mice, $A m J$ Pathol 182 (2013), pp. 1780-1789.

[9] M. Hussain, A. Javeed, M. Ashraf, Y. Zhao, M.M. Mukhtar and M.U. Rehman, Aspirin and immune system, Int Immunopharmacol 12 (2012), pp. 10-20.

[10] B.N. Cronstein, M.C. Montesinos and G. Weissmann, Sites of action for future therapy: an adenosine-dependent mechanism by which aspirin retains its antiinflammatory activity in cyclooxygenase-2 and NFkappaB knockout mice, Osteoarthritis Cartilage 7 (1999), pp. 361-363.

[11] D. Taubert, R. Berkels, N. Grosser, H. Schroder, D. Grundemann and E. Schomig, Aspirin induces nitric oxide release from vascular endothelium: a novel mechanism of action, BrJ Pharmacol 143 (2004), pp. 159-165.

[12] M. Grilli, M. Pizzi, M. Memo and P. Spano, Neuroprotection by aspirin and sodium salicylate through blockade of NF-kappaB activation, Science $\mathbf{2 7 4}$ (1996), pp. 1383-1385.

[13] M. Basselin, E. Ramadan, M. Chen and S.I. Rapoport, Anti-inflammatory effects of chronic aspirin on brain arachidonic acid metabolites, Neurochem Res 36 (2011), pp. 139-145.

[14] X.R. Gao, C.M. Adhikari, L.Y. Peng, X.G. Guo, Y.S. Zhai, X.Y. He, et al., Efficacy of different doses of aspirin in decreasing blood levels of inflammatory markers in patients with cardiovascular metabolic syndrome, J Pharm Pharmacol 61 (2009), pp. 1505-1510. 
Conflicts of interest : All authors declared no conflict of interest in the last 2 years.

No funding source.

Acknowledgments : This work was supported by INSERM, Assistance Publique Hôpitaux de Paris, RTRS Santé Mentale (Fondation Fondamental) and by Agence Nationale pour la Recherche (ANR: NEURO 2009, V.I.P. project). "This work was supported (in part) by the Investissements d'Avenir program managed by the ANR under reference ANR-11-IDEX-0004-02“. 